\title{
Canine perineal tumours and selected tumour markers
}

\section{Alexandra Valenčáková-Agyagosová ${ }^{1}$ Beáta Kiselová-Bileková2, Mária Figurová1 Valent Ledecký ${ }^{1}$, L’uboš Zábranský ${ }^{3}$, L'ubica Horňáková ${ }^{1}$}

${ }^{1}$ University of Veterinary Medicine and Pharmacy, Small Animal Clinic, Košice, Slovakia

${ }^{2}$ Institute of Nuclear and Molecular Medicine (INMM), Košice, Slovakia

${ }^{3}$ University of South Bohemia in České Budějovice, Faculty of Agriculture, České Budějovice, Czech Republic

Received May 1, 2018

Accepted Ostober 29, 2019

\begin{abstract}
The most frequent canine perineal tumour is the perianal (gland) adenoma (also known as the circumanal adenoma or the hepatoid adenoma). Tumour markers are substances that are produced by the body in response to cancer, or may be produced by cancer itself. Carcinoembryonic antigen (CEA) and tissue polypeptide specific antigen (TPSA) are tumour antigens that are markers of carcinogenesis, with significantly elevated serum concentrations in the case of some types of tumours. In our study it has been proven that dogs with a perineal tumour $(n=35)$ had a mean value of CEA $0.69 \mathrm{ng} \cdot \mathrm{ml}^{-1}$ compared to control dogs $(\mathrm{n}=150)$ with $0.67 \mathrm{ng} \cdot \mathrm{ml}^{-1}(P>0.05)$. In TPSA dogs with perineal tumour, the mean value of TPSA was $15.86 \mathrm{IU} \cdot 1^{-1} \mathrm{vs} 13.92 \mathrm{IU} \cdot 1^{-1}$ in the control dogs $(P<0.05)$. The results of the present study show that there is significant differences in TPSA between control dogs and group of dogs with a perineal tumour. Analysis of oncomarkers is a valuable tool for practitioners within small animal oncology, having an advantage over tissue biomarkers as the measurement procedure is non-invasive and shows dynamic changes of physiological and pathological states before clinical signs appear. Therefore, it may be used for an early detection of cancer.
\end{abstract}

\section{CEA, TPSA, statistical analysis, blood, radioimmunoassay}

The most frequent canine perineal tumour is the perianal (gland) adenoma (also known as the circumanal adenoma or the hepatoid adenoma) which is a common tumour that arises from the sebaceous glands surrounding the anus. It is so common that it accounts for $80 \%$ of all canine tumours that occur in the perineal area and that are seen most frequently in intact male dogs, because of the tumour's testosterone dependence. The malignant version is the perianal adenocarcinoma which is considered far less common than the perianal adenoma (Vos et al. 1989; Bennett et al. 2002).

Adenoma of the hepatoid gland occurs in the perineal region. Newly proliferated tumour tissue is encapsulated and the neoplasm is well demarcated from surrounding tissue. In a multilobulated pattern it has a rim of small reserve cells at the peripheral with central differentiation to large hepatoid cells.

Adenocarcinoma of the hepatoid gland is usually less well organized into trabecules or distinct lobules. It mostly consists of only one cell type which is poorly differentiated: hyperchromatic nuclei, little cytoplasm, and prominent nucleoli.

Under malignancy the hepatoid cells have an abundant eosinophilic cytoplasm and large nuclei with several prominent nucleoli and are mitotically active with small mitotic counts. It has been characterized as a feature of malignancy. Histologically, mitosis of hepatoid cells and/or invasion of neoplastic cells into the surrounding connective tissue or lymphatic vessels are the most important (Goldschmidt and Hendrick 2002).

Tumour markers are substances that are produced by the body in response to cancer, or may be produced by cancer itself. Some of them are specific to one cancer, while others

Address for correspondence:

Lubica Horňáková

Small Animal Clinic

Komenského 73

04181 Košice, Slovakia

Phone: +421917171 104

E-mail: lubica.hornakova@uvlf.sk

http://actavet.vfu.cz/ 
may be present in several types of cancer. They are generally used to evaluate the patient's response to treatment or to monitor for recurrence - the return of cancer after treatment (Vachani 2016).

Broadly, it is known that carcinoembryonic antigen (CEA) protein may appear in the blood with certain kinds of cancers, especially cancer of the large intestine (colon and rectal cancer). It may also be present in a subject with cancer of the pancreas, mammary gland, ovary, or lung. Tissue polypeptide specific antigen (TPSA) is one of the most valuable tumour markers, which is a complement to CA 19-9 (carbohydrate antigen 19-9) in the detection of the various epithelial cancers, including breast, colorectal, ovarian, lung and prostate cancer (Young et al. 2002; Fareed et al. 2012; Shao et al. 2012). The rising or declining value of a marker concentration in majority of malignancies predicts a progression or a remission of diseases. The diagnostic efficiency of tumour markers depends on a variety of factors such as sensitivity, specificity, positive predictive value (PPV) and negative predictive value (NPV). Sensitivity of these markers means the probability that the test results will be positive when a tumour is present. Their specificity is a screening parameter which indicates whether it may be used for describing the percentage of healthy individuals whose result is negative. The PPV describes the probability that the disease in question is actually present if the test result is positive. The NPV describes the probability that the disease is not actually present when the test result is negative (Malati 2007).

In this study, we attempted to examine CEA and TPSA in blood serum in dogs with perineal tumours. The aim of this study was to compare our results with these markers in clinically healthy dogs.

\section{Materials and Methods}

Dogs with a perineal tumour

The group of dogs with a perineal tumour $(\mathrm{n}=35)$ came from private breeding in the Kosice Region (Eastern Slovakia). They were of different ages (1-16 years), sexes (5 females and 30 males), intact. The breeds included the Mongrel $(\mathrm{n}=14)$, West Highland White Terrier $(\mathrm{n}=5)$, Cocker Spaniel, Yorkshire Terrier, Jack Russel Terrier, Fox Terrier $(\mathrm{n}=2$ each), Staffordshire Terrier, Shi-tzu, Labrador Retriever, German Shepherd, Maltese, Bichon, Dalmatian, and Pit Bull Terrier $(\mathrm{n}=1$ each). The mean age of dogs with the perianal adenoma was 10.7 (from 1 to 16) years and with the perianal adenocarcinoma 11.7 (from 9 to 15) years.

\section{Control dogs}

The group of examined control animals consisted of 150 clinically healthy dogs. One hundred of them were from the shelter (50 castrated males and 50 castrated bitches) of ages 0.5 to 10 years. Most dogs in our study were of mixed breeds.

The group of 50 castrated males consisted of the Mongrel $(n=31)$, German Shepherd $(n=14)$, Rottweiler $(\mathrm{n}=3)$, and Belgian Shepherd $(\mathrm{n}=2)$. The group of 50 castrated bitches consisted of the Mongrel $(\mathrm{n}=31)$, German Shepherd $(\mathrm{n}=12)$, Labrador Retriever $(\mathrm{n}=2)$, Chihuahua $(\mathrm{n}=3)$ and Yorkshire Terrier $(\mathrm{n}=2)$.

Fifty dogs (25 males and 25 females) from the control group were intact, at the age from 1 to 12 years. This group consisted of dogs that came to the Small Animal Clinic for basic examination before vaccination. Intact male dogs included the Mongrel, German Shepherd and Staffordshire Bull Terrier ( $\mathrm{n}=4$ each), Dalmatian $(\mathrm{n}=3)$, Jack Russel Terrier, Schnauzer and Cocker $(\mathrm{n}=2$ each), Dachshund, Slovak Rough-haired Pointer, Central Asian Shepherd, and Chihuahua $(n=1$ each). The intact bitches included the German Shepherd $(n=6)$, Mongrel $(n=4)$, Schnauzer, Yorkshire Terrier, Cane Corso, Rhodesian Ridgeback, French Bull Terrier and Czechoslovakian Shepherd $(\mathrm{n}=2$ each), Dobermann, Belgian Shepherd, and Papillon $(\mathrm{n}=1$ each).

Data on each patient comprised their signalment, medical history, and actual clinical status.

\section{Clinical examination}

Clinical examination consisted of measuring the body temperature, respiratory rate, and femoral pulse rate. Subsequently, the patient was examined systematically by way of topographical inspection and body palpation, including regional lymph nodes. Following the clinical examination, venous blood was taken from the v. cephalica antebrachii or the v. saphena medialis (lateralis). Blood samples were placed into test tubes with agglutinative gel using sterile single-use needles $(21 \mathrm{G} \times 38 \mathrm{~mm}, 0.8 \times 38 \mathrm{~mm})$. The blood was then centrifuged at $1,372 \times g$ for 10 min (Eppendorf centrifuge 5702, max RCF 3,000 $\times g$ ) and blood serum was separated. The remaining blood serum was stored at $-18{ }^{\circ} \mathrm{C}$ until the tumour markers were determined. The transport of the blood serum to the 
laboratory was carried out in a Pharmacy Refrigerator Portable Vaccine Cooler Box where the temperature was kept constant $\left(2-8^{\circ} \mathrm{C}\right)$ until arrival.

\section{Surgical removal}

The variety of procedures for removing tumours on the perineal part, and the choice of procedures were determined by the size, fixation to surrounding tissue and number of lesions. Premedication included administration of butorphanol $0.2 \mathrm{mg} / \mathrm{kg}$ i.v. (Butomidor $10 \mathrm{mg} / \mathrm{ml}$; Richter Pharma AG, Wels, Austria) and medetomidin hydrochloridum $0.015 \mathrm{mg} / \mathrm{kg}$ i.v. (Cepetor $1 \mathrm{mg} / \mathrm{ml}$; CP Pharma Handelsgesellschaft $\mathrm{mbH}$, Burgdorf, Germany). Anaesthesia was induced with propofol $4 \mathrm{mg} / \mathrm{kg}$ i.v. (Propofol 1\% MCT/LTC; Fresenius Kabi, Bad Homburg, Germany) and maintained with isoflurane (Isoflurin $1000 \mathrm{mg} / \mathrm{g}$; VETPHARMA ANIMAL HEALTH, S.L., Barcelona, Spain) in oxygen. The patient was prepared to surgery after preparation and draping surgical site. The skin around each tumour was incised with a scalpel, and the subcutaneous tissue was dissected. Adenomas of the perianal glands are usually easily dissected and the external anal sphincter rarely needs to be incised. This area is well-vascularised so it is necessary to control the bleeding during surgery by applying pressure with swabs. After checking that there was no active bleeding in the resected area, the subcutaneous tissue was closed using absorbable suture material (Polydox EP2 or EP3; CHIRANA T. Injecta, s.r.o., Prague, Czech Republic). The skin was closed with vertical mattress sutures using non-absorbable material (Daclon EP2; St. Vith, Belgium). Non-steroidal inflammatory drugs - meloxicam $0.04 \mathrm{mg} / \mathrm{kg}$ s.c. (Meloxidolor $5 \mathrm{mg} / \mathrm{ml} ; \mathrm{Le}$ Vet Beheer B.V., Oudewater, the Netherlands) were administered postoperatively to control pain. Before surgery, amoxicillin with clavulanic acid $15 \mathrm{mg} / \mathrm{kg}$ s.c. (Synulox RTU $100 \mathrm{ml}$; Zoetis, Prague, Czech Republic) was applied, continuing per os administration for 7 days (Synulox 50, 100 and $500 \mathrm{mg}$ tbl. ad us. vet.; Zoetis, Prague, Czech Republic)

\section{Histological examination}

In each animal $(\mathrm{n}=35)$, a sample $\left(1 \mathrm{~cm}^{3}\right)$ was collected from the margins between healthy and diseased tissue of the extirpated neoplasm and fixed in $10 \%$ neutral formalin. The sample was embedded in paraffin after $24 \mathrm{~h}$ and cut to $4 \mu \mathrm{m}$ slices that were then stained with haematoxylin-eosin (H\&E). All slides were examined under light microscope (Microscope RED-223 LED, Motic, Camera Moticam 3+, 3.0 MP, Xiamen, China) with $\times 40$ and $\times 100$ magnifications. Based on histopathological findings, the perineal tumours were classified according to the World Health Organisation scheme (Weiss and Frese 1974).

\section{Determination of CEA and TPSA}

The tumour markers were determined by immune radiometric analysis (IRMA) with use of commercially available kits in human medicine. Both determinations (CEA and TPSA) are based on the sandwich method using two monoclonal antibodies against two different epitopes in molecules, which work independently from each other. Standards, controls, and samples react simultaneously during incubation with solid phase catcher antibodies coated on beads and detector antibody (CEA - IMMUNOTECH s.r.o., Prague, Czech Republic; TPSA - IDL Biotech AB, Bromma, Sweden) (Ledecký et al. 2013; Valencakova-Agyagosova et al. 2014). However, we made two modifications: in the case ofCEAweused $10 \mu$ lofdog's serumand $300 \mu$ lofradioindicator, andinthecaseofTPSAitwas $50 \mu 1$ of dog's serum and $200 \mu 1$ of radio indicator.

\section{Statistical analysis}

The one-way ANOVA that serves for comparison of variances was used to compare CEA and TPSA values in clinically healthy dogs and dogs with confirmed tumours. Unpaired $t$-test was used to compare CEA and TPSA values in dogs with perianal adenoma compared to the dogs with perianal adenocarcinoma.

\section{Ethical approval}

We confirm that the owners of patients in this study and the head of Small Animal Clinic approved the medical process. Each owner's consent was obtained before the collection of samples. The study was conducted according to the regulations of the local Institutional Animal Care and Use Committee.

\section{Results}

Based on differences in histological features the tumours were classified as the perianal adenoma or the perianal adenocarcinoma. Our study included 35 dogs with perineal tumours: 26 with perianal adenomas and 9 with perianal adenocarcinomas.

The mean value of CEA in $35 \mathrm{dogs}$ with perineal tumours was $0.69 \mathrm{ng} \cdot \mathrm{ml}^{-1}(\min 0.08$ $\max 3.28 \mathrm{ng} \cdot \mathrm{ml}^{-1}$; Table 1$)$ against mean values of the control group $0.67 \mathrm{ng} \cdot \mathrm{ml}^{-1}(\min 0.07$ $\max 2.70)$. Differences between control and experimental groups were not significant $(P>0.05)$. Mean values of CEA in dogs with perianal adenoma $(\mathrm{n}=26$; Table 2$)$ were $0.70 \pm 0.67 \mathrm{ng} \cdot \mathrm{ml}^{-1}$ and values in dogs with perianal adenocarcinoma were $0.65 \pm 0.99 \mathrm{ng} \cdot \mathrm{ml}^{-1}$ 
$(\mathrm{n}=9$; Table 2). No significant difference was found between the dogs with perianal adenoma and perianal adenocarcinoma $(P=0.8639)$.

In the case of TPSA marker, the mean value of TPSA was $15.86 \mathrm{IU} \cdot 1^{-1}(\min 5.01-\max$ $39.89 \mathrm{IU} \cdot 1^{-1}$; Table 1) in dogs with a perineal tumour. Mean values of the control group were $13.92 \mathrm{IU} \cdot \mathrm{l}^{-1}\left(\min 6.90-\max 20.42 \mathrm{IU} \cdot \mathrm{l}^{-1}\right.$; Table 1$)$. We found a significant difference between the groups with perineal tumours and the control dogs $(P=0.0174)$.

In the case of perianal adenoma $(\mathrm{n}=26$; Table 2$)$, the mean values were $16.26 \pm 7.16 \mathrm{IU} \cdot \mathrm{l}^{-1}$ and in perianal adenocarcinoma $\left(\mathrm{n}=9\right.$; Table 2) $14.68 \pm 3.94 \mathrm{IU} \cdot \mathrm{l}^{-1}$.

No significant difference $(P>0.05)$ was noted between groups of dogs with the perianal adenoma and perianal adenocarcinoma.

\section{Discussion}

Defects in cell cycle progression often result in diseases such as cancer (Harashima et al. 2013). Accordingly, this essential life cycle is routinely used to assess cell health, as well as for cancer prognosis and diagnosis. Analysis of cell proliferation markers can be used to identify proliferating cells because of their distinct expression throughout the cell cycle. Antibodies specific to these proteins allow the distinction between actively dividing cells (positive expression) and quiescent cells (low or negative expression). This method of identifying proliferating cells is most common in pathological analyses of tumour tissue

Table 1. Concentrations of CEA $\left(\mathrm{ng} \cdot \mathrm{ml}^{-1}\right)$ and TPSA $\left(\mathrm{IU} \cdot \mathrm{l}^{-1}\right)$ tumour markers in the control group $(\mathrm{n}=150)$ compared to dogs with perineal tumours $(\mathrm{n}=35)$.

\begin{tabular}{lcccc}
\hline & $\begin{array}{c}\text { Control group } \\
\text { CEA }\left(\mathrm{ng} \cdot \mathrm{ml}^{-1}\right)\end{array}$ & $\begin{array}{c}\text { Dogs with perineal } \\
\text { tumours CEA }\left(\mathrm{ng} \cdot \mathrm{ml}^{-1}\right)\end{array}$ & $\begin{array}{c}\text { Control group } \\
\text { TPSA }\left(\mathrm{IU} \cdot \mathrm{l}^{-1}\right)\end{array}$ & $\begin{array}{c}\text { Dogs with perineal } \\
\text { tumours TPSA }\left(\mathrm{IU} \cdot \mathrm{l}^{-1}\right)\end{array}$ \\
\hline Mean & 0.67 & 0.69 & 13.92 & 15.86 \\
S.D. & 0.54 & 0.75 & 2.90 & 6.46 \\
Minimum & 0.07 & 0.08 & 6.90 & 5.01 \\
Maximum & 2.70 & 3.28 & 20.42 & 39.89 \\
Median & 0.53 & 0.39 & 14.25 & 14.84 \\
25\% Percentile & 0.21 & 0.24 & 11.80 & 12.48 \\
75\% Percentile & 0.96 & 0.96 & 15.89 & 18.68 \\
Significance & & $P=0.9591$ & \multicolumn{3}{c}{$P=0.0174$} \\
\hline
\end{tabular}

CEA - carcinoembryonic antigen; TPSA - tissue polypeptide specific antigen; S.D. - standard deviation

Table 2. Concentrations of CEA $\left(\mathrm{ng} \cdot \mathrm{ml}^{-1}\right)$ and TPSA $\left(\mathrm{IU} \cdot \mathrm{l}^{-1}\right)$ tumour markers in dogs with perianal adenoma $(\mathrm{n}=26)$ and perianal adenocarcinoma $(\mathrm{n}=9)$.

\begin{tabular}{|c|c|c|c|c|}
\hline & $\begin{array}{c}\text { Dogs with } \\
\text { perianal adenoma } \\
\mathrm{CEA}\left(\mathrm{ng} \cdot \mathrm{ml}^{-1}\right)\end{array}$ & $\begin{array}{l}\text { Dogs with perianal } \\
\text { adenocarcinoma } \\
\text { CEA }\left(\mathrm{ng} \cdot \mathrm{ml}^{-1}\right)\end{array}$ & $\begin{array}{c}\text { Dogs with perianal } \\
\text { adenoma } \\
\operatorname{TPSA}\left(\mathrm{IU} \cdot 1^{-1}\right)\end{array}$ & $\begin{array}{l}\text { Dogs with perianal } \\
\text { adenocarcinoma } \\
\text { TPSA }\left(\mathrm{IU} \cdot \mathrm{l}^{-1}\right)\end{array}$ \\
\hline Mean & 0.70 & 0.65 & 16.26 & 14.68 \\
\hline S.D. & 0.67 & 0.99 & 7.16 & 3.94 \\
\hline Minimum & 0.11 & 0.08 & 5.01 & 8.23 \\
\hline Maximum & 3.28 & 3.23 & 39.89 & 19.87 \\
\hline Median & 0.42 & 0.29 & 14.74 & 14.91 \\
\hline $25 \%$ Percentile & 0.31 & 0.19 & 12.56 & 11.22 \\
\hline $75 \%$ Percentile & 1.01 & 0.68 & 18.68 & 18.54 \\
\hline Significance & \multicolumn{2}{|c|}{$P>0.05$} & \multicolumn{2}{|c|}{$P>0.05$} \\
\hline
\end{tabular}

CEA - carcinoembryonic antigen; TPSA - tissue polypeptide specific antigen; S.D. - standard deviation 
using e.g. immunohistochemistry. However, it is important to highlight that the results obtained using this method are only indicative in respect of the number of proliferating cells rather than a direct measurement of the proliferation rate (Anonymous 2017a).

According to the National Cancer Institute, a biomarker is "a biological molecule found in blood, other body fluids, or tissues that is a sign of a normal or abnormal process, or of a condition or disease," such as cancer (Henry and Hayes 2012).

A biomarker is predictive if the effect of treatment (experimental group compared to control) is different for biomarker-positive patients compared to biomarker-negative patients (Ballman 2015; Pošiváková et al. 2016; Anonymous 2017a).

It can be a predictive or prognostic marker. A prognostic biomarker informs about a likely cancer outcome (e.g., disease recurrence, disease progression, death) independent of the treatment received. Screening refers to looking for cancer in patients who have no symptoms of the disease, while early detection is finding cancer at an early stage. In most cases, cancer can only be diagnosed using biopsy, and tumour markers are usually not used to diagnose cancer. However, markers can help determine if a cancer is likely in some patients. One of the most important uses for these markers is to monitor patients being treated for cancer, but they also can be used prognostic indicators of disease progression. They can indicate relapse during the follow-up period. Markers are also used to detect tumours that recur after the initial treatment. Some tumour markers can be useful once treatment has been completed and with no evidence of residual cancer left (Nagpal et al. 2016).

The CEA is a protein found in many types of cells associated with tumours, in the developing foetus, infection diseases, inflammatory bowel disease, pancreatitis, liver cirrhosis, colitis and some benign tumours. Despite the broad spectrum of its occurrence, CEA seems to be a suitable tool for monitoring the treatment of CEA-rich tumours. If the CEA level is high before treatment, it should fall to normal after successful therapy. The increasing CEA level indicates progression or recurrence of cancer (Anonymous 2017b).

Increased level of TPSA is important in detecting mainly epithelial tumours, pancreatic adenocarcinoma, and chronic pancreatitis but also in patients with benign pancreatic diseases as well as patients with other diseases.

In our work, we use commercially available human immune radiometric kits for determination of tumour markers in dogs, because in veterinary oncology similar kits are not available. Despite this, it appears that the human kits are useful for detecting the prognosis of canine tumour diseases such as benign and malignant perineal tumours.

A major problem in the identification of cancer biomarkers is a very low concentration of markers obtained from tissues with small, early-stage cancer lesions. Proteins and/or modified proteins may vary among individuals, between cell types, and even within the same cell under different stimuli or different disease states. Hence, it is difficult to know what value obtained from an individual is accurate and what value in different patients indicates a problem. Normal cells as well as cancer cells can produce most tumour markers. Tumour markers are not always present in early-stage cancers, on the other hand, tumour markers can be present because of noncancerous conditions (Nagpal et al. 2016; Pošiváková et al. 2018). An elevated level of oncomarkers can indicate tumour disease; however, there can also be other causes of the elevation (positive values). These markers can be higher in clinically healthy dogs, from non-evident inflammatory processes. In contrast, these markers can be found at low levels in patients with confirmed perineal tumours. Higher levels of both tumour markers were also found in the control group. As described above, the control group was composed of $150 \mathrm{dogs}$, both castrated/sterilized and intact, of both sexes. We assume that the levels of tumour markers can be affected by the oestral cycle, sex, castration, age, etc., which requires further study.

In conclusion, the analysis of oncomarkers is a valuable tool for the practitioners within small animal oncology, having an advantage over tissue biomarkers as the measurement 
procedure is non-invasive and shows dynamic changes of physiological and pathological states before clinical signs appear. Therefore, it may be used for early detection of cancer. The results of our study could be the basis for determination of TPSA markers in dogs with perineal tumours.

\section{Acknowledgements}

This publication was created within the project of the Medical University Park in Košice (MediPark, Košice), Phase I, ITMS: 26220220185, supported by the Operational Program Research and Development financed from the European Regional Development Fund (OP VaV2012/2.2/08-RO) contracts: OPVaV/12/2013 and NAZV QK1910438.

\section{References}

Anonymous 2017a: Understanding the eukaryotic cell cycle - a biological and experimental overview. Mini review. Bio-Rad Laboratories, Inc. Available at: bio-rad-antibodies.com

Anonymous 2017b: Tumor marker, CEA. Available at: MedicineNet.com. Viewed on 1/24/2017

Ballman KV 2015: Biomarker: predictive or prognostic? J Clin Oncol 33: 3968-3971

Bennett PF, DeNicola DB, Bonney P, Glickman N, Knapp SW 2002: Canine anal sac adenocarcinomas: clinical presentation and response to therapy. J Vet Intern Med 16: 100-104

Fareed KR, Soomro IN, Hameed K, Arora A, Lobo DN, Parsons SL, Madhusudan S 2012: Caspase-cleaved cytokeratin-18 and tumor regression in gastrooesophageal adenocarcinomas treated with neoadjuvant chemotherapy. World J Gastroenterol 18: 1915-1930

Goldschmidt MH, Hendrick MJ 2002: Tumors of the Skin and Soft Tissues. In: Meuten DJ (Ed.): Tumors in Domestic Animals. A Blackwell Publishing Professional, Iowa, pp. 45-117

Harashima H, Dissmeyer N, Schnittger A 2013: Cell cycle control across the eukaryotic kingdom. Trends Cell Biol 23: 345-356

Henry NL, Hayes DF 2012: Cancer biomarkers. Molec Oncol 6: 140-146

Ledecký V, Valenčáková-Agyagosová A, Lepej J, Frischová Z, Horňak S 2013: Determination of carcinoembryonic antigen and cancer antigen values with radioimmunoassay method in healthy females dogs. Vet Med 58: 277-283

Malati T. 2007: Tumour markers: an overview. Indian J Clin Biochem 22: 17-31

Nagpal M, Singh S, Singh P, Chauhan P, Zaidi MA 2016: Tumor markers: A diagnostic tool. Natl J Maxillofac Surg 7: 17-20

Pošiváková T, Hromada R, Pošivák J, Molnár L, Harvanová J 2018: Selected aspects of integrated environmental management. Annals of agricultural and environmental medicine: AAEM 25: 403-408

Pošiváková T, Švajlenka J, Lazar G, Pošivák J, Tothova C, Sopoliga I, Poráčová J 2016: Interaction of heavy metals and selected biochemical parameters in mouflons. Chemicke listy 110: 284-288

Shao MM, Chan SK, Yu AM, Lam CC, Tsang JY, Lui PC, Law BK, Tan PH, Tse GM 2012: Keratin expression in breast cancers. Virchows Arch 461: 313-322

Vachani C 2016: Patient Guide to Tumor Markers. The Abramson Cancer Center of the Univ. Pennsylvania. Available at: www.acvim.org/wwwfp/jvim/statguide.htm. Last modified April 28, 2016

Valencakova-Agyagosova A, Frischova Z, Sevcikova Z, Hajurka J, Lepej J, Szakallova I, Kredatusova G, Nagy V, Ledecky V 2014: Determination of carcinoembryonic antigen and cancer antigen (CA 15-3) in bitches with tumours on mammary gland: preliminary report. Veter Compar Oncol 12: 205-214

Vos BS, van den Ingh JH, Molenbeek RF, vanSluijs FJ 1989: Perineal tumours. J Vet Med, Series A 36: 739-749

Weiss E, Frese F 1974: Tumors of the skin. Bull Wld Hlth Org 50: 79-100

Young GD, Winokur TS, Cerfolio RJ, Van Tine BA, Chow LT, Okoh V, Garver RI Jr. 2002: Differential expression and biodistribution of cytokeratin 18 and desmoplakins in non-small cell lung carcinoma subtypes. Lung Cancer 36: 133-141 